Campos Neutrais - Revista Latino-Americana de Relações Internacionais Vol. 2, $\mathrm{N}^{\mathrm{O}}$ 2, Maio-agosto de 2020. Santa Vitória do Palmar - RS.

\title{
Modelos de proteção ao consumidor no que diz respeito à lei aplicável aos contratos internacionais de consumo e sugestões para o Direito brasileiro*
}

Lúcia Souza d'Aquino** $^{* *}$

Resumo: O presente artigo aborda três modelos identificados quanto à determinação da lei aplicável aos contratos de consumo internacionais. Através de uma metodologia de legislação comparada, são apresentados o modelo europeu - adotado também no Québec, na Argentina, no Japão e na República Dominicana -, o modelo brasileiro e o modelo chinês, que é semelhante ao panamenho. Pretende-se, após a análise desses modelos, verificar se o modelo existente, no Brasil, é o melhor e, caso contrário, sugerir um aprimoramento da proteção da parte vulnerável nessas situações.

Palavras-chave: Direito do Consumidor. Direito Internacional Privado. Contratos internacionais de consumo. Lei aplicável.

\section{Models of consumer protection regarding the law applicable to international consumer contracts and suggestions for Brazilian law}

\begin{abstract}
This article addresses three models identified in determining the law applicable to international consumer contracts. Through a methodology of comparative legislation, the European (also adopted in Quebec, Argentina, Japan, and the Dominican Republic), the Brazilian and the Chinese (which is similar to the Panamanian) models are presented. It is intended, after the review of these models, verify if Brazilian existing model is the best one, and, if it is not, make a suggestion to improve the protection of the vulnerable part in these situations.
\end{abstract}

Keywords: Consumer Law. Private International Law. International Consumer Contracts. Applicable law.

\section{Introdução}

O Direito do Consumidor tem experimentado um grande crescimento em diversos sistemas jurídicos em todo o mundo. Em razão da globalização e do crescimento descontrolado do consumismo, devido em grande parte às técnicas de publicidade persuasivas e à facilidade do comércio on-line, a disparidade de forças entre consumidor e fornecedor exige uma intervenção cada vez maior na legislação para proteger a parte vulnerável de tais relações.

No entanto, devido ao aumento do turismo e das relações comerciais transfronteiriças, é também crescente a necessidade de determinar a lei aplicável em caso de litígio entre consumidores e fornecedores domiciliados em países diferentes.

Surgem, assim, três modelos principais para determinar a lei aplicável a tais litígios: a abordagem substantivo-comparativa; a abordagem substantivo-comparativa, com a criação de um fator especial de conexão para a proteção do consumidor; e a abordagem

\footnotetext{
" Publicação original: D'AQUINO, Lúcia Souza. Models of consumer protection regarding the law applicable to international consumer contracts and suggestions for Brazilian law. Revista da Faculdade de Direito da Universidade Federal de Uberlândia, Uberlândia, v. 47, n. 1, p. 383-394, jan./jun. 2019. Disponível em: http://www.seer.ufu.br/index.php/revistafadir/article/view/48686.

** Doutora em Direito pela Universidade Federal do Rio Grande do Sul. Professora Substituta na Universidade Federal da Grande Dourados.
} 
Campos Neutrais - Revista Latino-Americana de Relações Internacionais Vol. 2, $\mathrm{N}^{\mathrm{O}}$ 2, Maio-agosto de 2020. Santa Vitória do Palmar - RS.

procedimental e alternativa.

Assim, o presente trabalho pretende apresentar e analisar os referidos modelos, com as suas vantagens e desvantagens, bem como apresentar a aplicação nos diferentes ordenamentos jurídicos e a posição dos organismos internacionais sobre o assunto, pretendendo mostrar qual deles é mais protetor para os consumidores em um mundo globalizado e se a legislação brasileira protege o consumidor de forma adequada.

\section{Abordagem substantivo-comparativa}

O modelo substantivo-comparativo baseia-se nas normas europeias relativas à proteção do consumidor nas relações transfronteiriças.

A defesa do consumidor, embora não esteja presente nas políticas da União Europeia com o merecido destaque desde o início ${ }^{1}$, é de inegável importância. Isso porque, segundo dados da própria União Europeia, existem, atualmente, mais de 508 milhões de consumidores (EUROPEAN COMISSION, 2016, p. 3).

É um número expressivo, cujo gasto representa mais da metade (57\%) do PIB da União Europeia (EUROPEAN COMISSION, 2016, p. 3). Portanto, é de absoluta relevância que tais cidadãos, como consumidores, gozem de proteção adequada em suas relações de consumo (WARD, 2009, p. 134).

O preâmbulo do Tratado de Roma, que constituía a Comunidade Europeia, previa, para o seu fim, "a melhoria constante das condições de vida e de trabalho dos seus povos" (COMISSÃO EUROPEIA, 1957).

Seu artigo $2^{\circ}$ previa a missão de promover "uma elevação acelerada do padrão de vida" nos Estados ${ }^{2}$. No entanto, não há proteção expressa aos consumidores ${ }^{3}$. Isso porque, naquela época, os consumidores eram considerados, apenas, em seu sentido econômico ${ }^{4}$, em razão da produção de bens e das políticas de concorrência. A legislação preconizava,

\footnotetext{
${ }^{1}$ Em sua origem, a União Europeia possuía uma concepção produtivista, focada em “edificar um espaço económico, um mercado susceptível de abarcar as mais poderosas economias europeias que, em lugar de se digladiarem, deveriam estabelecerem comunhão de esforços vias privilegiadas para o desenvolvimento." (FROTA, 2007, p. 17)

${ }^{2}$ "O Tratado de Roma, em seu art. $2^{\circ}$, define, inequivocamente, tais objectivos: a Comunidade Económica Europeia tem por missão promover um desenvolvimento harmonioso das atividades económicas no seu seio, uma expansão contínua e equilibrada do nível de vida." (FROTA, 2007, p. 17)

3“'Implicitamente, a referência ao consumidor pode ser deduzida, outrossim, do art. 2 do Tratado, relativo à promoção da melhoria do nível de vida, bem como do art. 30 do referido documento, que legitima determinadas medidas de efeito equivalente e restrições quantitativas necessárias à "proteção da saúde e da vida das pessoas". O primeiro benefício atribuído aos consumidores europeus foi, portanto, um simples reflexo da construção do mercado comum, no qual as empresas devem respeitar o jogo da livre concorrência". (FELLOUS, 2003, p. 101)

4“"A Europa econômica aí está: o consumidor é não a preocupação dominante enquanto sujeito de direitos, mas objecto do mercado, em paralelo com os factores de produção”. (FROTA, 2007, p. 18)
} 
Campos Neutrais - Revista Latino-Americana de Relações Internacionais Vol. 2, $\mathrm{N}^{\mathrm{O}}$ 2, Maio-agosto de 2020. Santa Vitória do Palmar - RS.

diretamente, a concorrência leal e, apenas indiretamente, o consumidor (MARQUES, 2000, p. 51).

Os fundadores da Comunidade Europeia tinham em mente que

a ação conjunta da livre circulação de fatores de produção (que em teoria conduziria à sua ótima distribuição) e da defesa da livre concorrência, complementada pelas políticas comunitárias de agricultura, comércio e transportes, permitiria ao consumidor comunitário incrementar seus ingressos e eleger entre uma oferta de bens de consumo superior em variedade, quantidade e qualidade, a preços inferiores.(MOLINA DEL POZO, 1997, p. 657)

No entanto, isso não ocorreu. É claro que o consumidor experimentou os efeitos do crescimento econômico, mas sua posição, em relação aos fornecedores, tornou-se mais vulnerável $^{5}$. A eliminação de fronteiras e barreiras para a circulação de mercadorias trouxe novas dificuldades de consumo. O consumidor se deparou com problemas, como, por exemplo, entender um rótulo escrito em um idioma diferente do seu ou como proceder, administrativa ou judicialmente, contra um produtor de outro país membro. ${ }^{6}$

A origem da política de defesa do consumidor data da Cúpula de Chefes de Estado e de Governo de 1973 (PEGADO, 2009, p. 78). Em sua comunicação final, os Estadosmembros expressaram a opinião de que a expansão econômica deve traduzir-se em melhor qualidade e em padrão de vida. Essa declaração é considerada o início da política comunitária dos consumidores.

O Programa de Ação de Informação e Proteção ao Consumidor foi aprovado em 1975, reconhecendo cinco direitos fundamentais do consumidor: proteção da saúde e segurança, proteção dos interesses econômicos, indenização por danos, informação e educação em termos de consumo e de representação. Devido ao seu sucesso, um segundo programa foi desenvolvido para o período 1980-85, e programas de ação foram implementados desde então. Em 1990, foi aprovado o primeiro Plano de Ação Trienal, cujos principais temas foram representação e participação ativa, informação ao consumidor e segurança.

Em 1993, com o Tratado de Maastricht, "se afigura lícito e avisado considerar que

\footnotetext{
5"It must (also) be noted that the balance between the European consumer and business is not an equal one [...] They (the consumers) act from a position of obvious disempowerment." (WARD, 2009, p. 133.)

6“Os fundadores da Comunidade não perceberam desde o início a necessidade dessa proteção. Necessidade esta que foi percebida, sobretudo a partir da década de 70, quando a mecanização e a massificação causaram grandes mudanças na produção e distribuição de produtos, despertando para a proteção deste vulnerável ator econômico". (FELLOUS, 2003, p. 100)
} 
Campos Neutrais - Revista Latino-Americana de Relações Internacionais Vol. 2, $\mathrm{N}^{\mathrm{O}}$ 2, Maio-agosto de 2020. Santa Vitória do Palmar - RS.

de uma autêntica e genuína política de consumidores se pode reclamar a Comunidade Europeia.” (FROTA, 2007, p. 129). ${ }^{7}$

A norma comunitária, em matéria de proteção e informação do consumidor, inserese nas cinco grandes áreas em que a atividade comunitária é distribuída no Segundo Programa de Ação: proteção do consumidor (alimentação, agricultura, cosméticos, têxteis, substâncias perigosas, especialidades farmacêuticas, veículos automóveis, produtos manufaturados); proteção do consumidor (publicidade enganosa, crédito ao consumidor, responsabilidade por produtos defeituosos, venda fora do local) - justificada pela desvantagem do consumidor em relação ao fornecedor -; a necessidade de protegê-lo de produtos defeituosos, de publicidade enganosa do consumidor; a necessidade de permitir ao consumidor uma escolha adequada; a proteção do consumidor; a informação e a educação; e a promoção dos interesses do consumidor.

$\mathrm{O}$ atual programa de ação visa consolidar e melhorar a segurança do produto por meio de vigilância eficaz do mercado; melhorar a educação, a informação e a sensibilização dos consumidores para os seus direitos, desenvolver uma base factual para a política dos consumidores e prestar apoio às organizações de consumidores, nomeadamente, tendo em conta as necessidades específicas dos consumidores vulneráveis; desenvolver e reforçar os direitos dos consumidores, em particular, através de ações regulamentares inteligentes, melhorando o acesso a soluções simples, eficientes, expeditas e de baixo custo, incluindo soluções alternativas de litígios; e apoiar a aplicação dos direitos do consumidor, reforçando a cooperação entre os órgãos nacionais de aplicação da lei e apoiando os consumidores com aconselhamento (PARLAMENTO EUROPEU E CONSELHO DA UNIÃO EUROPEIA, 2014).

A proteção dos consumidores na União Europeia tem se baseado na política prevista no Tratado sobre o Funcionamento da União Europeia, merecendo um capítulo específico ${ }^{8}$.

\footnotetext{
${ }^{7}$ No mesmo sentido: “Até agora, tínhamos a impressão de agirmos como clandestinos, mas agora, a partir de Maastricht, podemos dizer que a política comunitária de proteção aos consumidores recebeu os meios de atingir a maioridade. O novo tratado da União Européia contém uma base jurídica certa e incontestável autorizando uma política europeia em favor dos consumidores.") (CONSTANTINESCO; KOVAR, 1995, p. 15)

${ }^{8}$ TÍTULO XV. A DEFESA DOS CONSUMIDORES Artigo $169^{\circ}$ (ex-artigo $153^{\circ} \mathrm{TCE}$ ) 1 . A fim de promover os interesses dos consumidores e assegurar um elevado nível de defesa destes, a União contribuirá para a proteção da saúde, da segurança e dos interesses económicos dos consumidores, bem como para a promoção do seu direito à informação, à educação e à organização para a defesa dos seus interesses.

2. A União contribuirá para a realização dos objetivos a que se refere o $n^{\circ} 1$. através de:

a) medidas adotadas em aplicação do artigo $114^{\circ}$ no âmbito da realização do mercado interno;

b) medidas de apoio, complemento e acompanhamento da política seguida pelos Estados-Membros.
} 
No entanto, uma vez que as relações de consumo são cada vez mais complexas e não se restringem apenas à sua vertente de consumo, também, está prevista a proteção dos consumidores em outras políticas, como a agricultura ${ }^{9}$ e a concorrência ${ }^{10}$.

Atualmente, a política europeia do consumidor

\begin{abstract}
assegura a aplicação a todos os produtos e serviços de consumo, incluindo os vendidos em linha, de um conjunto de regras comuns em toda a UE;

garante condições de concorrência equitativas para as empresas e proíbe práticas comerciais desleais;

permite um acesso rápido, fácil e a baixo custo a mecanismos de resolução de litígios;

reduz os riscos em matéria de segurança dos produtos em toda a Europa, graças a uma colaboração e a uma fiscalização do mercado mais eficazes; garante a disponibilização de informação, aconselhamento e apoio no que respeita a questões relacionadas com a defesa dos consumidores;

protege os consumidores mais vulneráveis, como as crianças. (COMISSÃO EUROPEIA, 2016, p. 3)
\end{abstract}

3. O Parlamento Europeu e o Conselho, deliberando de acordo com o processo legislativo ordinário e após consulta ao Comité Económico e Social, adotarão as medidas previstas na alínea b, do n ${ }^{\circ}$.

4.As medidas adotadas, nos termos do $\mathrm{n}^{\circ} 3$, não obstam a que os Estados-Membros mantenham ou introduzam medidas de proteção mais estritas. Essas medidas devem ser compatíveis com os Tratados e serão notificadas à Comissão. (UNIÃO EUROPEIA, 2016)

${ }^{9}$ Artigo $39^{\circ}$ (ex-artigo $33^{\circ}$ TCE)

1. A política agrícola comum tem como objetivos: (...)

e) assegurar preços razoáveis nos fornecimentos aos consumidores.

Artigo $40^{\circ}$ (ex-artigo $34^{\circ} \mathrm{TCE}$ )

1. A fim de atingir os objetivos definidos no artigo $39^{\circ}$, é criada uma organização comum dos mercados agrícolas. Segundo os produtos, esta organização assumirá uma das formas seguintes:

a) regras comuns em matéria de concorrência;

b) uma coordenação obrigatória das diversas organizações nacionais de mercado;

c) uma organização europeia de mercado.

2. A organização comum, sob uma das formas previstas no $\mathrm{n}^{\circ} 1$, pode abranger todas as medidas necessárias para atingir os objetivos definidos no artigo $39^{\circ}$, designadamente: regulamentações dos preços; subvenções tanto à produção como à comercialização dos diversos produtos; medidas de armazenamento e de reporte; $\mathrm{e}$ mecanismos comuns de estabilização das importações ou das exportações. A organização comum deve limitar-se a prosseguir os objetivos definidos no artigo $39^{\circ}$ e deve excluir toda e qualquer discriminação entre produtores ou consumidores da União. Uma eventual política comum de preços deve assentar em critérios comuns e em métodos de cálculo uniformes. (UNIÃO EUROPEIA, 2016, p. 62-63)

${ }^{10}$ Artigo $102^{\circ}$ (ex-artigo $82^{\circ}$ TCE)

É incompatível com o mercado interno e proibido, na medida em que tal seja suscetível de afetar o comércio entre os Estados-Membros, o facto de uma ou mais empresas explorarem de forma abusiva uma posição dominante no mercado interno ou numa parte substancial deste.

Estas práticas abusivas podem, nomeadamente, consistir em:

a) Impor, deforma direta ou indireta, preços de compra ou de venda ou outras condições de transação não equitativas;

b) Limitar a produção, a distribuição ou o desenvolvimento técnico em prejuízo dos consumidores;

c) Aplicar, relativamente a parceiros comerciais, condições desiguais no caso de prestações equivalentes colocando-os, por esse facto, em desvantagem na concorrência;

d) Subordinar a celebração de contratos à aceitação, por parte dos outros contraentes, de prestações suplementares que, pela sua natureza ou de acordo com os usos comerciais, não têm ligação com o objeto desses contratos. (UNIÃO EUROPEIA, 2016, p. 89) 
Campos Neutrais - Revista Latino-Americana de Relações Internacionais Vol. 2, $\mathrm{N}^{\mathrm{O}}$ 2, Maio-agosto de 2020. Santa Vitória do Palmar - RS.

Vê-se, portanto, que houve uma grande evolução no direito da União Europeia desde o Tratado de Roma, havendo uma previsão entre as políticas de defesa do consumidor de proteção dos consumidores mais vulneráveis.

Desde a década de 1990, planos de ação foram instituídos, os quais direcionam a política do consumidor para a proteção específica de alguns aspectos. O Programa Plurianual, para o período 2014-2020, encontra-se em vigor e objetiva:

\begin{abstract}
assegurar um elevado nível de proteção dos consumidores, habilitá-los e colocálos no centro do mercado interno, no âmbito de uma estratégia global de crescimento inteligente, sustentável e inclusivo. Para alcançar esse objetivo, o Programa contribuirá para a proteção da saúde, da segurança e dos interesses jurídicos e económicos dos consumidores, bem como para a promoção do seu direito à informação, à educação e a organizarem-se em defesa dos seus interesses, e apoiará a integração dos interesses dos consumidores noutros domínios de intervenção. O Programa deve complementar, apoiar e acompanhar as políticas dos Estados-Membros. (PARLAMENTO EUROPEU E CONSELHO DA UNIÃO EUROPEIA, 2014)
\end{abstract}

No que diz respeito à lei aplicável aos contratos envolvendo consumidores, o Tratado de Roma I estabelece que a lei aplicável aos contratos de consumo é a do domicílio do consumidor ${ }^{11}$, uma vez que tais contratos são constituídos tendo em conta a atividade comercial ou profissional do fornecedor nesse país ${ }^{12}$, deixando pouca margem de escolha de direito, o que só pode ocorrer nos casos previstos no $\mathrm{n}^{\mathrm{o}} 2$, do artigo $6^{\mathrm{o}} .^{13}$

Além da União Europeia, algumas outras legislações seguem esse modelo. $\mathrm{Na}$ província de Québec, no Canadá, a escolha da lei aplicável não pode privar o consumidor

\footnotetext{
${ }^{11}$ Artigo $6^{\circ}$ Contratos celebrados por consumidores 1 . Sem prejuízo do disposto nos artigos $5^{\circ}$ e $7^{\circ}$, os contratos celebrados por uma pessoa singular, para uma finalidade que possa considerar-se estranha à sua actividade comercial ou profissional ( o consumidor»), com outra pessoa que aja no quadro das suas actividades comerciais ou profissionais («o profissional»), são regulados pela lei do país em que o consumidor tem a sua residência habitual desde que o profissional:

a) Exerça as suas actividades comerciais ou profissionais no país em que o consumidor tem a sua residência habitual, ou

b) Por qualquer meio, dirija essas actividades para este ou vários países, incluindo aquele país, e o contrato seja abrangido pelo âmbito dessas actividades. (PARLAMENTO EUROPEU E CONSELHO DA UNIÃO EUROPEIA, 2008)

${ }^{12}(25)$ Os consumidores deverão estar protegidos pelas disposições do seu país de residência habitual que não são derrogáveis por acordo, na condição de o contrato de consumo ter sido celebrado no quadro das actividades comerciais ou profissionais exercidas pelo profissional no país em questão. A mesma protecção deverá ser garantida no caso de o profissional não exercer as suas actividades comerciais ou profissionais no país em que o consumidor tem a sua residência habitual mas dirigir as suas actividades, por qualquer meio, para esse país ou vários países, incluindo o do consumidor, e o contrato seja celebrado no quadro de tais actividades. (PARLAMENTO EUROPEU E CONSELHO DA UNIÃO EUROPEIA, 2008)

${ }^{13}$. Sem prejuízo do ${ }^{\circ} 1$, as partes podem escolher a lei aplicável a um contrato que observe os requisitos do $\mathrm{n}^{\mathrm{o}} 1$, nos termos do artigo $3^{\circ}$. Esta escolha não pode, porém, ter como consequência privar o consumidor da protecção que lhe proporcionam as disposições não derrogáveis por acordo da lei que, na falta de escolha, seria aplicável com base no $\mathrm{n}^{\circ}$ 1. (PARLAMENTO EUROPEU E CONSELHO DA UNIÃO EUROPEIA, 2008)
} 
Campos Neutrais - Revista Latino-Americana de Relações Internacionais Vol. 2, $\mathrm{N}^{\mathrm{O}}$ 2, Maio-agosto de 2020. Santa Vitória do Palmar - RS.

da proteção conferida pelas disposições obrigatórias da lei do país de residência do consumidor. ${ }^{14}$

No mesmo sentido, o Direito Internacional Privado da República Dominicana determina a competência dos tribunais dominicanos para a solução de controvérsias relativas aos contratos de consumo, quando o consumidor aí tiver domicílio. ${ }^{15}$

O novo Código Civil e Comercial da Nação Argentina, seguindo o mesmo exemplo, determina os casos em que os contratos de consumo são regidos pela lei do domicílio do consumidor: se a celebração do contrato foi precedida de atividade exercida no domicílio do consumidor; se o fornecedor recebeu o pedido no Estado de domicílio do consumidor; se o consumidor foi induzido pelo fornecedor a viajar a um Estado estrangeiro para fazer o pedido; e se os contratos de viagem incluem os custos de transporte e acomodação. $^{16}$

No direito japonês, por outro lado, o modelo europeu também tem influência, mas é dado foco à manifestação do consumidor em relação às regras obrigatórias. ${ }^{17}$

\footnotetext{
14“3117. Le choix par les parties de la loi applicable au contrat de consommation ne peut avoir pour résultat de priver le consommateur de la protection que lui assurent les dispositions impératives de la loi de l'État où il a sa résidence si la conclusion du contrat a été précédée, dans ce lieu, d'une offre spéciale ou d'une publicité et que les actes nécessaires à sa conclusion y ont été accomplis par le consommateur, ou encore, si la commande de ce dernier y a été reçue.

Il en est de même lorsque le consommateur a été incité par son cocontractant à se rendre dans un État étranger afin d'y conclure le contrat.

En l'absence de désignation par les parties, la loi de la résidence du consommateur est, dans les mêmes circonstances, applicable au contrat de consommation." (QUÉBEC, 1991.)

15“Art. 16. Competencia de los tribunales dominicanos en derecho patrimonial. Los tribunales dominicanos serán competentes en las siguientes materias, referentes a derecho patrimonial: (...)

4) Contratos celebrados por consumidores, cuando el consumidor tenga su domicilio en la República Dominicana y la otra parte ejerciere actividades profesionales en la República Dominicana, o por cualquier medio hubiere dirigido su actividad comercial hacia la República Dominicana y el contrato estuviere comprendido en el marco de dichas actividades. En otro caso, se aplicará la regla contenida en el numeral 1 de este artículo;" (REPÚBLICA DOMINICANA, 2014.)

16“ARTICULO 2655.- Derecho aplicable. Los contratos de consumo se rigen por el derecho del Estado del domicilio del consumidor en los siguientes casos:

a) si la conclusión del contrato fue precedida de una oferta o de una publicidad o actividad realizada en el Estado del domicilio del consumidor y éste ha cumplido en él los actos necesarios para la conclusión del contrato;

b) si el proveedor ha recibido el pedido en el Estado del domicilio del consumidor;

c) si el consumidor fue inducido por su proveedor a desplazarse a un Estado extranjero a los fines de efectuar en él su pedido;

d) si los contratos de viaje, por un precio global, comprenden prestaciones combinadas de transporte y alojamiento." (ARGENTINA, 2014.)

${ }^{17}$ Special Rules for Consumer Contracts

Article 11

(1) Even if the law governing the formation and effect of a contract (except for a labor contract) that is concluded between a consumer (the term "consumer" as used in this article means an individual who becomes a contractual party neither in nor for the purpose of business) and a business operator (the term "business operator" as used in this article means a juridical person or other association or foundation, or an individual who becomes a contractual party in or for the purpose of business), which is referred to in the following provisions of this article as a "consumer contract", is, according to a choice or change of governing
} 
Campos Neutrais - Revista Latino-Americana de Relações Internacionais Vol. 2, $\mathrm{N}^{\mathrm{O}}$ 2, Maio-agosto de 2020. Santa Vitória do Palmar - RS.

\section{Abordagem Substantivo-Comparativa com a criação de um fator especial de conexão para a proteção do consumidor}

A proteção ao consumidor, na legislação brasileira, deriva da Constituição Federal de 1988, centrada no Estado Social de Direito, que visa garantir os direitos do cidadão e sua dignidade ${ }^{18}$, "valor supremo que atrai o conteúdo de todos os direitos fundamentais do homem", que pode ser vista nas previsões sobre a existência da dignidade como finalidade da ordem econômica, a justiça social como objetivo da ordem social e as garantias de educação, desenvolvimento e preparação das pessoas para o exercício da cidadania (SILVA, 2013, p. 107). A dignidade da pessoa humana, portanto, é o eixo central que deve nortear a interpretação dos princípios constitucionais ${ }^{19}$.

law pursuant to Article 7 or Article 9 respectively, a law other than the law of the place where the consumer habitually resides, the specific mandatory rules in the law of the consumer's habitual residence shall also apply to matters subject to such mandatory rules with regard to the formation and effect of the consumer contract, provided that the consumer expresses his/her will to the business operator to the effect that such mandatory rules should apply.

(2) If the parties have not chosen a law to govern the formation and effect of their consumer contract pursuant to Article 7, the formation and effect of such consumer contract shall be, notwithstanding Article 8, subject to the law of the consumer's habitual residence.

(3) Even if a law other than the law of the consumer's habitual residence has been chosen to govern the formation of a consumer contract pursuant to Article 7, the specific mandatory rules in the law of his/her habitual residence shall exclusively apply to matters subject to such mandatory rules with regard to the formalities of the consumer contract, notwithstanding paragraphs 1,2 and 4 of the preceding article, provided that the consumer expresses his/her will to the business operator to the effect that such mandatory rules should apply.

(4) If the law of the consumer's habitual residence has been chosen to govern the formation of a consumer contract pursuant to Article 7, and if the consumer expresses his/her will to the business operator to the effect that the law of his/her habitual residence should exclusively apply to the formalities of the consumer contract, the formalities of the consumer contract shall be governed by the law of the consumer's habitual residence, notwithstanding paragraphs 2 and 4 of the preceding article.

(5) If the parties have not chosen a law to govern the formation of their consumer contract pursuant to Article 7 , the formalities of the consumer contract shall be governed by the law of the consumer's habitual residence, notwithstanding paragraphs 1,2 and 4 of the preceding article.

(6) The preceding paragraphs 1 through 5 are not applicable in any of the following cases: (i) the business operator's establishment which relates to the consumer contract is located in a jurisdiction other than the jurisdiction of the consumer's habitual residence, and the consumer goes to the jurisdiction of the business operator's establishment and concludes a consumer contract in that jurisdiction; except where the consumer has been solicited by the business operator to conclude the consumer contract in that jurisdiction.

(ii) the business operator's establishment which relates to the consumer contract is located in a jurisdiction other than the jurisdiction of the consumer's habitual residence, and the consumer goes to the jurisdiction of the business operator's establishment and receives or is to receive complete performance by the business operator in that jurisdiction; except where the consumer has been solicited by the business operator to receive complete performance to be performed by the business operator in that jurisdiction.

(iii) at the time the consumer contract is concluded, the business operator is unaware of the location of the consumer's habitual residence and has reasonable ground for such unawareness.

(iv) at the time the consumer contract is concluded, the business operator has misidentified the counterparty as not being a consumer and has reasonable ground for such misidentification. (JAPAN, 2006.)

${ }^{18 “ " O}$ grupo dos direitos fundamentais atua como um núcleo, ao redor do qual se pretende que gire o direito privado. Um novo sistema solar, no qual o Sol é a pessoa. Não se trata de mera comprovação fática ou de instalação legal passiva, senão de verdadeiro princípio ativo e, portanto, estruturante do sistema." (LORENZETTI, 2010, p. 1257-258.)

${ }^{19}$ Ressalte-se que a dignidade da pessoa humana é fundamento da República Federativa do Brasil (art. $1^{\circ}$, 
Campos Neutrais - Revista Latino-Americana de Relações Internacionais Vol. 2, $\mathrm{N}^{\mathrm{O}}$ 2, Maio-agosto de 2020. Santa Vitória do Palmar - RS.

Como cumprimento desse objetivo, o art. $5^{\circ}$, que trata dos direitos e garantias fundamentais, prevê uma ação positiva do Estado no cumprimento dessas garantias e, às vezes, a abstenção das pessoas, evitando relações que violem tais direitos. Além disso, e no que diz respeito ao fundamento da livre iniciativa ${ }^{20}$, prevê que a ordem econômica deve garantir a todos uma existência digna, limitando-se à proteção do consumidor ${ }^{21}$.

Entre as garantias fundamentais, está a provisão de proteção ao consumidor, a ser promovida pelo Estado ${ }^{22}$. Em cumprimento a esta disposição e ao disposto no art. 48 do Ato das Disposições Constitucionais Transitórias ${ }^{23}$, em 1990, foi sancionado o Código de Defesa do Consumidor (CDC) (BRASIL, 1990).

O CDC é uma norma de ordem pública e interesse social ${ }^{24}$, que tem como premissa e princípio básico a vulnerabilidade do consumidor $^{25}$. Desse modo, irradia para outras normas do ordenamento jurídico brasileiro a proteção conferida à parte fragilizada das relações de consumo.

Nesse sentido, o Código de Processo Civil, em vigor desde 2015, dispõe de regras específicas quanto à competência territorial para a resolução de litígios de consumo quando o consumidor tem domicílio no país ${ }^{26}$. Por sua vez, a questão da lei aplicável não foi contemplada pelo novo Código.

III), que visa, entre outras coisas, a construção de uma sociedade livre, justa e solidária (art. $3^{\circ}$, I) e considerando todos "iguais perante a lei, sem distinção de qualquer espécie, garantindo aos brasileiros e estrangeiros residentes no Brasil a inviolabilidade do direito à vida, à liberdade, à igualdade, à segurança e à propriedade" (art. 5 ${ }^{\circ}$, caput). (BRASIL, 1988.)

20 “Art. $1^{\circ}$ A República Federativa do Brasil, formada pela união indissolúvel dos Estados e Municípios e do Distrito Federal, constitui-se em Estado Democrático de Direito e tem como fundamentos: (...)

IV - os valores sociais do trabalho e da livre iniciativa;" (BRASIL, 1988)

21 “Art. 170. A ordem econômica, fundada na valorização do trabalho humano e na livre iniciativa, tem por fim assegurar a todos existência digna, conforme os ditames da justiça social, observados os seguintes princípios: (...)

V - defesa do consumidor;" (BRASIL, 1988)

22 “Art. $5^{\circ}$ Todos são iguais perante a lei, sem distinção de qualquer natureza, garantindo-se aos brasileiros e aos estrangeiros residentes no País a inviolabilidade do direito à vida, à liberdade, à igualdade, à segurança e à propriedade, nos termos seguintes:

XXXII - o Estado promoverá, na forma da lei, a defesa do consumidor;" (BRASIL, 1988)

23 “Art. 48. O Congresso Nacional, dentro de cento e vinte dias da promulgação da Constituição, elaborará código de defesa do consumidor." (BRASIL, 1988.)

24 “Art. $1^{\circ} \mathrm{O}$ presente código estabelece normas de proteção e defesa do consumidor, de ordem pública e interesse social, nos termos dos arts. $5^{\circ}$, inciso XXXII, 170, inciso V, da Constituição Federal e art. 48 de suas Disposições Transitórias.” (BRASIL, 1990.)

25 "Art. $4^{\circ}$ A Política Nacional das Relações de Consumo tem por objetivo o atendimento das necessidades dos consumidores, o respeito à sua dignidade, saúde e segurança, a proteção de seus interesses econômicos, a melhoria da sua qualidade de vida, bem como a transparência e harmonia das relações de consumo, atendidos os seguintes princípios:

I - reconhecimento da vulnerabilidade do consumidor no mercado de consumo;” (BRASIL, 1990.)

26 “Art. 22. Compete, ainda, à autoridade judiciária brasileira processar e julgar as ações: (...)

II - decorrentes de relações de consumo, quando o consumidor tiver domicílio ou residência no Brasil;" (BRASIL, 2015). Para maiores discussões a respeito do tema, ver: D'AQUINO; MACHADO, 2017, p. 373-390. 
Campos Neutrais - Revista Latino-Americana de Relações Internacionais Vol. 2, $\mathrm{N}^{\mathrm{O}}$ 2, Maio-agosto de 2020. Santa Vitória do Palmar - RS.

No entanto, o Projeto de Lei n. 3.514/2015, que trata, principalmente, do comércio eletrônico, possui norma específica quanto à legislação aplicável aos contratos de consumo, alterando a Lei de Introdução ao Direito Brasileiro (LINDB) ${ }^{27}$, bem como alterando o art. 101 do CDC, permitindo a escolha da lei aplicável no caso de ações referentes a contratos de consumo desde que mais favorável ao consumidor ${ }^{28}$.

\section{Abordagem Procedimental e Alternativa}

Neste último modelo, é possível escolher a legislação aplicável desde que a escolha seja feita pelo consumidor e se limite a leis que contenham elementos de conexão tradicionais.

É o modelo adotado pela China, por exemplo, que permite ao consumidor escolher a lei aplicável em alguns $\operatorname{casos}^{29}$, respeitando o interesse público que proíbe a escolha de uma lei que prejudique o consumidor ${ }^{30}$.

No mesmo sentido, o Direito Internacional Privado do Panamá introduz um regime de direito aplicável aos contratos desiguais ${ }^{31}$ e inova, ao inserir, em seu art. $8^{\circ}$, um conjunto de princípios internacionais fundamentais, incluindo o melhor interesse do

\footnotetext{
27“"Art. $9^{\circ}$-B. O contrato internacional de consumo, entendido como aquele realizado entre um consumidor pessoa natural e um fornecedor de produtos e serviços cujo estabelecimento esteja situado em país distinto daquele de domicílio do consumidor, reger-se-á pela lei do lugar de celebração ou, se executado no Brasil, pela lei brasileira, desde que mais favorável ao consumidor.

$\S 1^{\circ} \mathrm{Se}$ a contratação for precedida de qualquer atividade negocial ou de marketing, por parte do fornecedor ou de seus representantes, dirigida ao território brasileiro ou nele realizada, em especial envio de publicidade, correspondência, e-mails, mensagens comerciais, convites, prêmios ou ofertas, aplicar-se-ão as disposições da lei brasileira que possuírem caráter imperativo, sempre que mais favoráveis ao consumidor.

$\S 2^{\circ}$ Os contratos de pacotes de viagens internacionais ou viagens combinadas, que envolvam grupos turísticos ou serviços de hotelaria e turismo, com cumprimento fora do Brasil, contratados com agências de turismo e operadoras situadas no Brasil, reger-se-ão pela lei brasileira.” (BRASIL, 2015.)

28 " $\$ 2^{\circ}$ Aos conflitos decorrentes do fornecimento a distância internacional, aplica-se a lei do domić́lio do consumidor, ou, desde que mais favorável a este, a norma estatal escolhida pelas partes, assegurado, em qualquer hipótese, o acesso do consumidor à Justiça.” (BRASIL, 2015.)

29 "ARTICLE 42

A consumer contract is governed by the law of the consumer's habitual residence. Where the consumer chooses the law of the place where the commodity or the service is provided, or where the business operator does not engage in any business activity in the habitual residence of the consumer, the law of the place where the commodity or service is provided shall be applied." (PEOPLE'S REPUBLIC OF CHINA, 2010.)

${ }^{30 " S o c i a l ~ p u b l i c ~ i n t e r e s t ~ i s ~ n o t ~ d e f i n e d ~ i n ~ e i t h e r ~ t h e ~ C i v i l ~ C o d e ~ o r ~ t h e ~ C o n t r a c t ~ L a w, ~ b u t ~ i t ~ i s ~ g e n e r a l l y ~}$ understood in China to mean social morals and public order. For purposes of application of foreign law, the social public interest has an elastic nature and provides the people's courts with much discretionary power to make decisions on an ad hoc basis. For example, if application of a foreign law would adversely affect state ownership in the form of stocks or shares in a company, or the application would be deemed detrimental to the consumer interest, the foreign law may not be applied by Chinese people's court on the ground of social public interest." (ZHANG, 2006, p. 320.)

31 "Artículo 89. Se entiende por contratos desiguales o de adhesión los contratos en los que la parte más débil no tiene facultad para negociar las cláusulas esenciales de dichos contratos. Se entenderá como cláusulas esenciales o de adhesión las cláusulas que fijan el precio, las condiciones de ejecución del contrato y las cláusulas de solución de conflictos. La imposición de una de esas cláusulas se entenderá como el medio de comprobación de un contrato desigual." (REPÚBLICA DE PANAMÁ, 2014.)
} 
Campos Neutrais - Revista Latino-Americana de Relações Internacionais Vol. 2, $\mathrm{N}^{\mathrm{O}}$ 2, Maio-agosto de 2020. Santa Vitória do Palmar - RS.

consumidor $^{32}$. Em seu art. 95, a Lei determina como lei aplicável onde a transação foi concluída referente ao contrato de consumo, abrindo espaço para escolha do consumidor em alguns $\operatorname{casos}^{33}$.

\section{Considerações finais}

A necessidade global de proteção do consumidor tem exigido a atuação dos estados no sentido de, entre outras medidas, determinar a legislação aplicável nos casos de conflito de leis em razão de contratos internacionais de consumo.

Assim, existem três modelos principais para determinar a lei aplicável nestes casos: a abordagem substantiva comparativa, adotada pela União Europeia e seguida por Québec, República Dominicana, Argentina e Japão; o enfoque substantivo-comparativo com a criação de um fator especial de conexão para a proteção do consumidor, com base na legislação brasileira; e o enfoque procedimental e alternativo, com ênfase particular na China e no Panamá.

Ciente dessas disposições, a International Law Association, no ano de 2016, durante a Conferência de Joanesburgo, apresentou as suas "Diretrizes sobre as melhores práticas no direito aplicável à proteção internacional dos consumidores", com sugestão para a adoção de normas com as melhores práticas sobre regras especiais sobre a legislação aplicável aos contratos internacionais de consumo.

A sugestão final do comitê foi a seguinte:

Final Suggestion of the Committee of a mixed Model Rule:

Article 1. Consumer Contracts

1. An international consumer contract shall be governed by the law of the country where the consumer has his habitual residence, provided that the professional:

a. pursues his commercial or professional activities in the country where the consumer has his habitual residence, or

b. by any means, directs such activities to that country or to several countries

32 "Artículo 8. Los principios fundamentales de la comunidad internacional son parte de las reglas de aplicación del juez, como el interés superior del niño y el interés del consumidor, que privan sobre cualquier otro aspecto; la igualdad, equidad, buena fe y lealtad negocial, la seguridad jurídica sobre los actos, la básica territorialidad de la ley, la personalidad de las normas sobre el Estado, la capacidad y derecho de familia, la proporcionalidad, los derechos adquiridos sin fraude al derecho naturalmente competente, la protección a la parte más débil, las obligaciones internacionales erga omnes y los derechos derivados del ius cogens y la responsabilidad ambiental y aquellos principios universales de justicia aplicables." (REPÚBLICA DE PANAMÁ, 2014.)

33 “Artículo 95. Los contratos del consumidor se rigen por la ley del lugar donde concluyó la transacción. A elección del consumidor, este podrá recurrir a la jurisdicción de su domicilio, a la del lugar de conclusión del contrato o a la que le sea más favorable, en función del principio del interés superior del consumidor. Se entiende por la ley más favorable la ley de la reparación y protección más apropiada al interés del consumidor." (REPÚBLICA DE PANAMÁ, 2014.) 
Campos Neutrais - Revista Latino-Americana de Relações Internacionais Vol. 2, $\mathrm{N}^{\mathrm{O}}$ 2, Maio-agosto de 2020. Santa Vitória do Palmar - RS.

\begin{abstract}
including that country, and in both cases, the contract falls within the scope of such activities.

2. If the requirements in points (a) or (b) of paragraph 1 are not fulfilled, the law applicable to a contract between a consumer and a professional shall be governed by the law choose by the parties and in absence of choice, by the law of the country where the goods or services were supplied.

3. The parties may choose the law applicable, provide that this law is more favorable to the consumer.

4.The parties may choose between the law of the habitual residence of the consumer, the place of conclusion or the place of performance of the contract, and in this case, the more favorable to the consumer is the law that assures the protective remedies or redress more adequate to the interest of the consumer in the dispute.(INTERNATIONAL LAW ASSOCIATION, 2016)
\end{abstract}

Entende-se que o modelo apresentado é uma sugestão adequada para a proteção do consumidor em contratos internacionais de consumo. Como se vê, o Projeto de Lei $\mathrm{n}$. 3.514/2015 vai no mesmo sentido que a International Law Association, mostrando a necessidade de aprovação do Projeto de Lei para a proteção do consumidor.

\title{
Bibliografia
}

ARGEnTINA. Código Civil y Comercial de la Nación. Ley 26.994, de 2014. Disponível em: https://goo.gl/6DHwc3. Acesso em: 24 out. 2020.

BRASIL. Ato das Disposições Constitucionais Transitórias. 1988.Disponível em: https://goo.gl/fILVlX. Acesso em: 20 out. 2020.

BRASIL. Constituição (1988). Constituição da República Federativa do Brasil de 1988. Disponível em: https://goo.g1/HwJ1Q. Acesso em: 20 out. 2020.

BRASIL. Lei n. 13.105, de 16 de março de 2015. Disponível em: https://goo.gl/9wv14x. Acesso em: 19 out. 2020.

BRASIL. Lei n. 8.078, de 11 de setembro de 1990. Disponível em: https://goo.gl/P7nUD. Acesso em: 20 out. 2020.

BRASIL. Projeto de Lei n. 3.514/2015. Disponível em: https://goo.gl/uLWyhD. Acesso em: 19 out. 2020.

COMISSÃO EUROPEIRA. Compreender as políticas da União Europeia: Consumidores.

Luxemburgo: Serviço das Publicações da União Europeia, 2016. Disponível em: https://op.europa.eu/en/publication-detail/-/publication/2f0e7c29-0d03-11e6-ba9a-01aa75ed71a1 .

Acesso em: 24 out. 2020.

CONSTANTINESCO, Vlad; KOVAR, Robert. Traité sur l'Union Européenne, commentaire article par article. Paris: Economica, 1995.

D'AQUINO, Lúcia Souza; MACHADO, Lucca Peracchi Pinheiro. Cláusula de Eleição de Foro em contratos internacionais de consumo: diálogos entre o Código de Defesa do Consumidor e o Novo Código de Processo Civil. In: MARQUES, Claudia Lima; REICHELT, Luis Alberto (Org.). Diálogos entre o Direito do Consumidor e o Novo CPC. São Paulo: Revista dos Tribunais, 2017. p. 373-390.

FELLOUS, Beyla Esther. Proteção do consumidor no Mercosul e na União Européia. São Paulo: Revista dos Tribunais, 2003.

FROTA, Mario. Código de Defesa do Consumidor: balanço, efectividade e perspectivas. Novas 
Campos Neutrais - Revista Latino-Americana de Relações Internacionais Vol. 2, $\mathrm{N}^{\mathrm{O}}$ 2, Maio-agosto de 2020. Santa Vitória do Palmar - RS.

tendências do direito do consumidor na Europa. Revista de Direito do Consumidor, São Paulo, v. 57, p. 129-161, jan./mar. 2006.

FROTA, Mário. Direito Europeu do Consumo: Reflexo das Políticas de Consumidores na União Europeia. Curitiba: Juruá, 2007.

HUO, Zhengxin. Highlights of China's New Private International Law Act: From the Perspective of Comparative Law. Revue Juridique Thémis, v. 45, p. 637-684, 2011.

INTERNATIONAL LAW ASSOCIATION. Johannesburg Conference (2016): International Protection of Consumers. Final Report. Disponível em: https://goo.gl/4BESpQ. Acesso em: 19 out. 2020.

JAPAN. Act on General Rules for Application of Laws of 2006. Disponível em: https://goo.gl/2VMccv. Acesso em: 19 out. 2020.

JUNMING, Luo. Choice of law for contracts in China: a proposal for the objectivization of standards and their use in conflicts of law.Indiana International \& Comparative Law Review, v. 6(2), p. 439-459, 1996. Disponível em: https://goo.gl/ECuxVB. Acesso em: 19 out. 2020.

LORENZETTI, Ricardo Luis. Teoria da Decisão Judicial: Fundamentos de Direito. 2. ed. São Paulo: Revista dos Tribunais, 2010.

MARQUES, Claudia Lima. Normas de proteção do consumidor (especialmente, no comércio eletrônico) oriundas da União Européia e o exemplo de sua sistematização no Código Civil Alemão de 1896 - notícia sobre as profundas modificações no BGB para incluir a figura do consumidor. Revista de Direito Privado, São Paulo, v. 1, n. 4, p. 50-93, out. 2000.

MOLINA DEL POZO, Carlos Francisco. Manual de Derecho de la Comunidad Europea. 3. ed. Madrid: Trivium, 1997.

NISHITANI, Yuko. Party Autonomy and its Restrictions by Mandatory Rules in Japanese Private International Law: Contractual Conflicts Rules. In: BASEDOW, Juergen; BAUM, Harald; NISHITANI, Yuko (ed.). Japanese and European Private International Law in Comparative Perspective. Tübingen: Mohr Siebeck, 2008. p. 77-104.

PARLAMENTO EUROPEU E CONSELHO DA UNIÃO EUROPEIA. Regulamento (CE) $n^{0}$ 593/2008 do Parlamento Europeu e do Conselho de 17 de Junho de 2008sobre a lei aplicável às obrigações contratuais (Roma I). Disponível em: https://eur-lex.europa.eu/legalcontent/PT/TXT/HTML/?uri=CELEX:32008R0593\&from=pt. Acesso em: 24 out. 2020.

PARLAMENTO EUROPEU E CONSELHO DA UNIÃO EUROPEIA. Regulamento (UE) $\mathbf{n}^{\mathbf{0}}$ 254/2014 do Parlamento Europeu e do Conselho de 26 de fevereiro de 2014relativo a um programa plurianual «Consumidores» para o período 2014-2020 e que revoga a Decisão $\mathrm{n}^{\circ}$ 1926/2006/CE. Disponível em: https://eur-lex.europa.eu/legalcontent/PT/TXT/HTML/?uri=CELEX:32014R0254\&from=PT. Acesso em: 24 out. 2017.

PEGADO, Jorge Liz. EU Consumer Protection Law and Policy. Recent Developments and Perspectives. In: BOURGOIGNIE, Thierry (org.). L'intégration économique régionale et la Protection du consommateur. Québec: Éditions Yvon Blais, 2009.

PEOPLE'S REPUBLIC OF CHINA. Decree of the President of the People's Republic of China N. 36 (Law of the People's Republic of China on the Laws Applicable to Foreign-related Civil Relations). 2010. Disponível em: https://goo.gl/ABYwmz. Acesso em: 19 out. 2020.

QUÉBEC. Code Civil du Québec. 1991. LégisQuébec. Disponível em: https://goo.gl/kkdU6R. Acesso em: 19 out. 2020.

REPÚBLICA DE PANAMÁ. Ley n. 7, de 8 de mayo de 2014, que adopta el Código de Derecho Internacional Privado de la República de Panamá. Disponível em: https://goo.gl/98RcHv. Acesso em: 19 out. 2020.

REPÚBLICA DOMINICANA. Ley n. 544-14 de Derecho Internacional Privado de la 
Campos Neutrais - Revista Latino-Americana de Relações Internacionais Vol. 2, $\mathrm{N}^{\mathrm{O}}$ 2, Maio-agosto de 2020. Santa Vitória do Palmar - RS.

República Dominicana, de 15 de octubre de 2014. Disponível em: https://goo.gl/DhP26C. Acesso em: 19 out. 2020.

SILVA, José Afonso da. Curso de Direito Constitucional Positivo. 36. ed. São Paulo: Malheiros, 2013.

UNIÃO EUROPEIA. Tratado sobre o Funcionamento da União Europeia (Versão

Consolidada). Jornal Oficial da União Europeia, 07 jun. 2016. Disponível em: https://eur-

lex.europa.eu/resource.html?uri=cellar:9e8d52e1-2c70-11e6-b497-

01aa75ed71a1.0019.01/DOC_3\&format=PDF. Acessoem: 24out. 2020.

WARD, Ian. A Critical Introduction to European Law. 3. ed. Cambridge: Cambridge University Press, 2009.

YING, Yu. Chinese Approaches to Reform Consumer Protection law: Substantive Law and Conflict Law. Revista de Direito do Consumidor, São Paulo, v. 25, n. 103, p. 143-154, jan./fev. 2016.

ZHANG, Mo. Choice of Law in Contracts: A Chinese Approach. Northwestern Journal of International Law \& Business, v. 26(2), p. 289-333, 2006. p. 320. Disponível em:

https://goo.gl/4X9a1A. Acesso em: 19 out. 2020. 